\title{
The influence of music learning cultures on the construction of teaching-learning conceptions
}

\author{
Amalia Casas-Mas, ${ }^{1}$ Juan Ignacio Pozo ${ }^{2}$ and Ignacio Montero ${ }^{2}$ \\ ${ }^{1}$ Real Conservatorio Superior de Música de Madrid. Departamento de Pedagogía. c/Santa Isabel, 53, CP: \\ 28012, Madrid, Spain \\ ${ }^{2}$ Universidad Autónoma de Madrid. Facultad de Psicología. C/ Iván Pavlov, 6, CP: 28049, Madrid, Spain \\ acasasmas@gmail.com; nacho.pozo@uam.es; nacho.montero@uam.es
}

Current research in music education tends to put the emphasis on learning processes outside formal academic contexts, both to rethink and to renew academic educational formats. Our aim is to observe and describe three music learning cultures simultaneously, including formal, non-formal and informal settings: Classical, Jazz and Flamenco, respectively. We observed the conceptions of learning, teaching and evaluation within the framework of implicit theories. We used multiple-choice questionnaires to infer the profiles of these conceptions in 30 guitarists who are starting out on their professional careers in the three cultures and analysed whether there are related profiles. The results show that: (a) the Flamenco culture differs significantly from the others in the conception of teaching; $(b)$ the three cultures are most alike in the conception of evaluation, for which conceptions are more sophisticated; (c) the classical culture is closer to constructive conceptions and farther from direct positions, while the opposite is true of Flamenco.

\section{Introduction}

Music education, like other fields of education, increasingly needs to review its forms of transmission and foster changes in the development of learners and future professionals, which are compatible with society's new learning demands. Among the factors fostering this cultural change are the epistemological beliefs and conceptions sustained by the different agents of musical education - both teachers (Hallam, 2007; Bautista, 2009; López-Íñiguez et al., 2014) and learners (Bautista et al., 2012; Marín et al., 2012). Many studies have been conducted on experts and novices and on types of learning strategies, focusing more on quality than quantity of practice (Jørgensen, 2002; Duke et al., 2009). There is also increasing interest in finding out what musicians focus their attention on during the different stages of studying and practicing sheet music (Williamon et al., 2002; Chaffin et al., 2003) or music without a score (Green, 2001, 2011).

To date, most of the research on teaching and learning conceptions in different domains, such as mathematics, physics, psychology or music, has been conducted in formal education contexts, such as academic institutions of Western European tradition. In the case of music, these are conservatories and regulated music schools. But is the same true in other musical cultures? 
The idea for this research arose from the fact that one of the researchers is a music teacher at the Royal Conservatory of Music in Madrid (Spain) and was trained in the academic tradition, but is a jazz and flamenco performer. For her work as a performer, she was trained in non-formal and informal settings, where she experienced other ways of teaching and learning music. Therefore the study takes a novel stance by using a simultaneous approach to analyse conceptions of teaching and learning in formal and non-formal music contexts. We assume that different contexts promote different types of learning cultures in relation to the education and transmission of knowledge. In the domain of music, this allows us to observe a wide variety of aspects of learning, such as concepts, procedures, attitudes and emotions that learners inform us about. We then describe the impact of various educational contexts on beliefs about teaching, learning or evaluation of knowledge.

\section{Teaching and learning cultures as triggers for implicit conceptions}

Based on cognitive archaeology models, Donald (1991, 1993) claims that each culture requires different mental activity including its own formats of representation and social communication. The same might apply to cultural contexts designed to promote learning and teaching, which generate their own educational settings, tools and communicative systems. Olson and Bruner (1996) propose four models, which represent not only conceptions regarding culture and the relationship between minds and culture, but also mental concepts and beliefs about teaching and learning. These models allow us to understand the ways people construct meanings about the learning and teaching in relation to educational issues.

These conceptions may influence educational practices in different cultural contexts because they express the formats for transmitting knowledge that evolve according to the concept of learner held. The implicit theories seem to contribute to the discourse that participants use in educational situations, so we assume that they may be found when teachers and learners talk about these processes (Pozo et al., 2006). These beliefs evolve from theories epistemologically linked from realism towards constructivist perspectivism (Bautista et al., 2010; López-Íñiguez et al., 2013; Scheuer, de la Cruz y Pozo, 2002).

The use of the Direct Theory implies that the learner's mind is a blank slate which the teacher tries to remedy by offering his/her knowledge by demonstration, like an artisan, fostering the learner's imitation of the teacher's own performance. This theory is considered one of the oldest views of learning. In the Interpretative Theory, the teacher's knowledge is expressed by means of explanation and declarative knowledge. Faithful reproduction of this knowledge can be demanded anyway, but conceiving the learner as 'knower' implies that the teacher understands that a series of psychological processes take place in the learner's mind. The activation of those processes will affect the learning that the teacher expects the learner to achieve, and it may thus be included in the interpretative theory.

Teachers using Constructive Theory tend to see the learner as a thinker, which involves a conceptual change. The learner's reconstruction of reality and knowledge is what makes learning possible. The student's role is therefore active. Now, for the learner to be constructive in addition to being a thinker, he/she must learn to regulate and manage cognitive and motor processes for him/herself, and be able to establish a pact between 
self-produced knowledge and culturally accumulated, teacher-mediated knowledge. In other words, the learner must construct a personal representation of the music he/she plays and composes without ignoring the surrounding culture.

For De Corte (1996), and many other authors, constructivism is not to teach knowledge and skills transferring to an 'empty' mind of a passive learner; instead teaching is designed to promote student's cognitive processes, so that they can construct meanings, senses, knowledge and skills actively provided on the basis of their previous cognitive structures (Piaget, 1974) and within their ZPD (Vygostky, 1933/1978). The crux of the matter is the transformative role and constructive of the epistemic subject (Bransford et al., 2000; Sawyer, 2006). Then, the teacher's role is to guide and supervise the start-up of the learner's reflexive, metacognitive, emotional and affective processes, as the main way of fostering his/her understanding and autonomy, which is what will enable the student to take on the role of expert, in the words of Olson and Bruner. Teaching thus focuses on the interactive relationship among learner, teacher and learning material or instrument.

A relationship can be established between the different teaching-learning cultures proposed by Olson and Bruner and the implicit theories that the individuals participating in each may develop (as shown in Table 1). But so far, it has not been easy to find many 'pure' cases of each theory (Bautista et al., 2012; Marín et al., 2013). They are not closed profiles, and it seems that people share certain principles or others, depending on where they are thinking or acting. We will explain this below.

\section{Conceptions of music teaching and learning in different educational dimensions}

Studies such as those by Klatter et al. (2001), Kember (2001) and Peterson and Irving (2008) describe the degrees of consistency in the theories of students from the end of elementary school to university level in different educational scenarios. The idea described by Entwistle (2007) as representational multiplicity refers to the fact that the restrictions of a given dimension may give rise to different representations. Thus, the theories of learning and teaching may be composed of a set of situated (contextualised) conceptions based on different assumptions, forming profiles, which are theoretically 'hybrid', as directinterpretative, interpretative-constructive and constructive. So far, a direct-constructive profile has not been found (Casas \& Pozo, 2008) due to conceptual rupture that makes it difficult for them to coexist.

In general, the interpretative theory coexists with both the direct and the constructive theories (López-Íñiguez et al., 2014), implying that it not just a 'transition theory' towards the constructive theory, but also a 'hinge theory' from which it is necessary to make a conceptual change. From the standpoint of conceptual change, it is considered that the development of a more sophisticated theory (constructive) does not require the replacement of the intuitive theories (direct and interpretative), but rather, the ability to integrate multiple perspectives (see Pozo \& Gómez Crespo, 2005).

Would it be more common to find hybrid profiles in all cultures? Can we find pure profiles more consistently in some cultures than in others? Below we shall describe the different social settings of music teaching and learning and see whether there are multiple representations within the different cultural groups. Could one cultural group consistently 
Table 1 Implicit theories about learners' minds regarding culturally configured elements of the teaching-learning process. Adapted from Olson and Bruner (1996) and Pérez Echeverría, Mateos, Pozo, \& Scheuer (2001)

\begin{tabular}{|c|c|c|c|c|c|c|}
\hline Implicit theory & $\begin{array}{l}\text { Concept of } \\
\text { learner }\end{array}$ & What is acquired & $\begin{array}{l}\text { What makes learning } \\
\text { possible }\end{array}$ & Role of teacher & Role of learner & $\begin{array}{l}\text { Concept of } \\
\text { teacher }\end{array}$ \\
\hline Direct theory & Doer & Skill/ability & Ability to do & Demonstrator & Imitation & Craftsperson \\
\hline $\begin{array}{l}\text { Interpretative } \\
\text { theory }\end{array}$ & Knower & Knowledge & Ability to learn & Expositor & Comprehension & Authority \\
\hline $\begin{array}{l}\text { (Postmodern } \\
\text { theory) }\end{array}$ & Thinker & Beliefs & Ability to think & Collaborator & Interpretation & Colleague \\
\hline $\begin{array}{l}\text { Constructive } \\
\text { theory }\end{array}$ & Expert & $\begin{array}{l}\text { 'Objective' knowledge } \\
\text { and expertise }\end{array}$ & $\begin{array}{l}\text { Ability to contribute to } \\
\text { cultural store }\end{array}$ & $\begin{array}{l}\text { Information } \\
\text { manager }\end{array}$ & $\begin{array}{l}\text { Knowledge } \\
\text { constructor }\end{array}$ & Consultant \\
\hline
\end{tabular}


express itself differently regarding different educational dimensions? If those differences do appear, what might they be based on?

\section{Culture and music learning}

We shall begin by defining the term 'culture' anthropologically as a system of public representations endowed with public meanings (Sperber, 1996). Such public (in the sense of shared) representations are only connected to what they represent by the meaning attributed to them by those who produce or use them. By 'cultural representations' the author refers to those that are very common in a human group; therefore, to analyse cultural representations is to explain why many persons share some of them. This is why the author defends the idea of 'epidemiology of cultural representations', which is based on how representations are shared in a more or less generalised way without a clear boundary between cultural and individual representations.

Most music educational research focuses on observing the teaching processes at institutional sites, or what we shall call academic cultures, based on the premise that music learning is the result of being exposed to methodical, formally sequenced music teaching. The mediation tools or external representations which have been analysed are also based on notation, generally classical (Gruson, 1988; Woody, 1999; Hultberg, 2002; McPherson, 2005; Hallam, 2007; Casas \& Pozo, 2008; Bautista et al., 2009; López-Íñiguez \& Pozo, in press; Marín et al., 2013).

During the past 20 years there has been increasing interest in considering non-formal and informal contexts within institutional settings and applying them to teaching (DunbarHall \& Wemyss, 2000; Wang \& Humphreys, 2009; Robinson, 2010), as well as various forms of informal music learning outside institutional settings (Folkestad, 1998; Green, 2001, 2008; Shah, 2006). This is part of the shift in focus from teaching to learning, and thus from teacher to learner.

This may lead to understanding the situation as an opposition between oracy and literacy, however, Lilliestam (1996) claims that rather than viewing it as in opposition or a dichotomy, it should be seen as a continuum where different cultures have different degrees (and types) of literacy. Today it is more relevant to speak of oral and literate strategies for different types of aims and which work more or less well for different purposes.

Taking Folkestad's (2004) idea that 'creative music making takes place in a process of interaction between the participants' musical experience and competence, their cultural practice, the tools, the instruments and the instructions, altogether forming the affordances in the creative situation' (pp. 87-88) we cannot establish associations that simplify the formal and informal contexts according to the tools they use. Nevertheless, it is a definition using Vygotskian terms, from which we do see that these tools, instruments and instructions, tend to be organised differently according to whether they are expressed by means of sheet music or other types of representations (e.g. gestures). Furthermore, they develop from different experiences and competencies favoured in each.

It is very well known that musicians of the classical tradition prioritise notation compared with non-classical musicians. Moreover, the idea of regular, constant practice is crucial to classical musicians but not such a high priority to non-classical musicians, 
Table 2 Differences between the poles of the Formal and Informal contexts in musical education, following Folkestad (2006) and Trilla (1997)

\begin{tabular}{|c|c|c|}
\hline & FORMAL & INFORMAL \\
\hline Planning & Activity sequenced beforehand & $\begin{array}{l}\text { Activity not sequenced } \\
\text { beforehand }\end{array}$ \\
\hline Goal & $\begin{array}{l}\text { The activity focuses on how to learn to } \\
\text { work/play/compose }\end{array}$ & $\begin{array}{l}\text { The activity focuses on } \\
\text { the way of work- } \\
\text { ing/playing/composing }\end{array}$ \\
\hline Participants & $\begin{array}{l}\text { Arranged by the teacher, usually the } \\
\text { person who leads the activity (not } \\
\text { necessarily a teacher in the formal } \\
\text { sense, but someone who leads and } \\
\text { organises the learning activity, e.g. } \\
\text { one of the musicians in the group). } \\
\text { This position does not have to be } \\
\text { static, although it usually is }\end{array}$ & $\begin{array}{l}\text { The process proceeds by } \\
\text { the interaction of the } \\
\text { participants in the } \\
\text { activity }\end{array}$ \\
\hline Motivation & $\begin{array}{l}\text { Sometimes there may be conflict and } \\
\text { differences between teacher's and } \\
\text { learners' motivations }\end{array}$ & $\begin{array}{l}\text { Described as a } \\
\text { self-chosen, voluntary } \\
\text { learning }\end{array}$ \\
\hline Place & Within institutions & Outside institutions \\
\hline $\begin{array}{l}\text { Learning Style (nature } \\
\text { and quality of the } \\
\text { process) }\end{array}$ & Learning to play from sheet music & Learning to play by ear \\
\hline $\begin{array}{l}\text { Leadership in the } \\
\text { activity (who takes } \\
\text { the decisions about } \\
\text { the activity) }\end{array}$ & Didactic teaching & $\begin{array}{l}\text { Open, self-regulated } \\
\text { learning }\end{array}$ \\
\hline Intentionality & High & Low \\
\hline
\end{tabular}

who may practice much more sporadically and intensively, and use recordings as everyday tools (Green, 2001, 2008).

\section{From formal and non-formal to informal contexts in music education}

In connection with the above, the contexts in which each culture develops are not formal or informal because of the tools they use, but rather due to the set of cultural practices. Similarly, it would be a prejudice to claim that formal music learning is a synonym of western classical music using sheet music, and that informal learning is restricted to popular music transmitted by ear (Middleton, 1981; Folkestad, 2006). What is learned and how the elements are interconnected are not shaped by the type of music itself, but rather by a given approach to music that uses certain tools (representations, processes, contents and conditions) as mediators for people developing within a given context. These approaches are what we call learning cultures. Table 2 shows the differences between the formal and informal poles, following Folkestad (2006) and Trilla (1997). 
Between the two poles we can find a wide range of grey, but it is possible to define the ends and midpoint as follows. At one end are the musicians who come from an academic culture, dominated by education at conservatories and structures governed by evaluation and accreditation, as well as courses and degree structures. In the middle, there is a field of education which is gradually being included in formalised education but still often situated in independent schools. An example would be some kinds of educational structures distributed in courses and degrees, but with parallel accreditation to formal education, so it might be called a non-formal environment.

Finally, there is a musical education environment based on informal education, with no defining structure of courses, no degree or official certification. Music education encompasses a complex family social system, including the learner's close and extended family, with teachers as references in informal learning. We believe that this threefold distinction is legitimate to describe different types of objectives, not only musical, which would in turn establish different types of priorities for the music, the musical parameters sought and valued, and therefore its impact on the type of practice that different cultures would prioritise (Trilla, 1997).

Such contexts have received little attention in music education research, although they are increasingly considered. Most research into informal musical education focuses on pre-university educational environments (e.g. Schippers, 1996; Seifried, 2006; GeorgiiHemming \& Westvall, 2010; Gower, 2012), on concepts, influences, tastes and musical preferences of the youngest students (e.g. Howe \& Sloboda, 1991; Lamont et al., 2003) and teacher training programmes (Wang \& Humphreys, 2009; Wright \& Kanellopoulos, 2010; Robinson, 2012), sometimes trying to answer the question of integrating cultures in compulsory education classrooms and other occasions intended to apply to formal education models of popular music as a means to introduce classical music.

However, as Green (2008) says about popular music and informal learning, it is valuable in and for itself. Hence our purpose to observe the conceptions of music in both formal and informal realms, giving each of them their own intrinsic value. We shall first need to clarify certain definitions of the types of music that we will consider, because language is a means for constructing and approaching reality.

\section{Towards a definition of musical culture}

Since the 1980s there has been much debate regarding the definition of 'popular' music and its distinction from 'art music' and 'folk' (Middleton, 1981). As explained above, it would be an oversimplification to directly associate art music to formal learning, and folk and popular music to informal and non-formal learning. Art music is what we define nowadays as music from a Western European Classical perspective that includes several types, such as Baroque, Romantic, Classical and 20th century music (Elliott, 1989). It has been labelled as serious music and in Spanish-speaking countries labelled as música culta. This implies that other kinds of music which are not labelled as such would not classify as serious or cultured - folk music on the one hand, but even more so, popular music. 'Just as addicts of serious music had regarded popular music with distaste or disgust, so folk-music 
Table 3 Folk, art and popular music; an axiomatic triangle. Taken from Tagg (1982)

\begin{tabular}{|c|c|c|c|c|}
\hline Characteristic & & $\begin{array}{l}\text { Folk } \\
\text { Music }\end{array}$ & $\begin{array}{l}\text { Art } \\
\text { Music }\end{array}$ & $\begin{array}{l}\text { Popular } \\
\text { Music }\end{array}$ \\
\hline \multirow[t]{2}{*}{ Produced and transmitted by } & Primarily professionals & & $x$ & $x$ \\
\hline & Primarily amateurs & $\mathrm{x}$ & & \\
\hline \multirow[t]{2}{*}{ Mass distribution } & Usual & & & $x$ \\
\hline & Unusual & $\mathrm{x}$ & $\mathrm{x}$ & \\
\hline \multirow{3}{*}{$\begin{array}{l}\text { Main mode of storage } \\
\text { and distribution }\end{array}$} & Oral transmission & $\mathrm{x}$ & & \\
\hline & Musical notation & & $\mathrm{x}$ & \\
\hline & Recorded sound & & & $x$ \\
\hline \multirow{2}{*}{$\begin{array}{l}\text { Type of society in which } \\
\text { the category of music } \\
\text { mostly occurs }\end{array}$} & Nomadic or agrarian & $x$ & & \\
\hline & $\begin{array}{l}\text { Agrarian or industrial } \\
\text { Industrial }\end{array}$ & & $\mathrm{x}$ & $\mathrm{x}$ \\
\hline \multirow{2}{*}{$\begin{array}{l}\text { Written theory and } \\
\text { aesthetics }\end{array}$} & Uncommon & $\mathrm{x}$ & & $x$ \\
\hline & Common & $\mathrm{x}$ & $x$ & \\
\hline \multirow[t]{2}{*}{ Composer/Author } & Anonymous & $x$ & & \\
\hline & Non-anonymous & & $\mathrm{x}$ & $x$ \\
\hline
\end{tabular}

performers and scholars frequently viewed popular music with disdain. There was 'good', 'pure' popular music, which was the authentic music of the people, and could be called 'folk', or perhaps 'traditional' music; and there was 'bastardised', 'contaminated' music of the people, which was dismissed by derogatory terms such as 'popular', 'commercial', or even 'urban'" (Blacking, 1978, pp. 7-9).

Following Tagg (1982), popular music, unlike art music, is conceived for mass distribution (in the positivist definition of Middleton, 1990) to large and often socioculturally heterogeneous groups of listeners (in the sociological essentialism definition of Middleton, 1990). Whether the people are regarded as an active, progressive historical subject or a manipulated dupe varies. But the music is stored and distributed in nonwritten form, only possible in an industrial monetary economy where it becomes a commodity, and in a capitalist society subject to the laws of 'free' enterprise, according to which it should ideally sell as much as possible of as little as possible to as many as possible.

The argument exists that popular music cannot be analysed using only traditional tools of musicology, because it is neither conceived nor designed to be stored or distributed as notation, a large number of important parameters of musical expression being either difficult or impossible to encode in traditional notation. One of its great difficulties is the description of emotional aspects in music either occurring sporadically or being avoided altogether, and mostly 'immediate' aspects (such as sound, timbre, electro-musical treatment, ornamentation, etc.), which are relatively unimportant - or ignored - in the analysis of art music but extremely important in popular music.

On the one hand Traditional or Folk music is characterised in this point of view by being produced and transmitted by amateurs, transmitted and stored in oral tradition to smaller, local audiences, in societies which are mostly nomadic or agrarian and with no known composers or authors. Flamenco music in its deepest origins shared some 
common characteristics with folk music. But nowadays it is defined as urban music of the 20th century, like other Mediterranean music belonging to popular culture (Fado, Neapolitan Song, Rebetika, Rai, Ughniya, Arabesk ... ), like Jazz. On the other hand, some classical music (such as Indian Classical Music) still does not meet the description of formal education and would belong to the traditional music group. However, traditional music would also include other kinds of music than folk style.

Nevertheless, we refer in this study to the formal context of western classical music defined above and transmitted in the academic culture, although we are fully aware of the nuances, and we will call it the Classical culture. Similarly, we shall refer hereinafter by non-formal and informal learning to popular music to Jazz culture and Flamenco culture, respectively. Although being non-formal or informal will depend on the above characteristics, we explain below why this classification was used in the cultures selected for this study.

In Spain there are currently three different music cultures, in terms of formal and informal realms, from which many others may be explained. Madrid is a large city that can concentrate a significant amount of musicians and provide most of the sample needed for observing how people share certain types of beliefs.

It seems that there is a small problem in establishing that Classical and Jazz cultures belong to formal and non-formal respectively, as defined above. However, Flamenco is popular music, as Jazz is, although there are significant differences in their social contexts. It is true that at a semi-professional level learners are supervised by teachers as in other cultures. But these apprentices carry a significant musical baggage of learning in the home environment (Howe \& Sloboda, 1991), and not exclusive to the instrument, but a more global learning (in percussion, singing and dancing). In fact, teachers are usually the most experienced members of the family (both close and distant), who learners often call 'uncle'. This previous background, which learners would have, has been defined as informal context.

It is a great opportunity to compare a highly formalised context of Classical with two different cultures, which in turn differ subtly from each other, and therefore cannot have the same consideration although they are both popular music. This may be a historic moment for this observation, because the traditional formats tend to merge or disappear with globalisation and can offer different learning profiles of much value. For this reason we aim to observe simultaneously the educational beliefs in Classical music, Flamenco and Jazz, which could allow us to see whether there are really any differences in the conceptions they advocate in educational situations.

Classical culture. One of the features of the classical culture of this study is that it takes place in specifically designed places and institutions, such as the conservatory Real Conservatorio Superior de Música, where teachers have been selected by competition or specific tests. Teaching follows a curriculum of Artistic Teaching issued by the national government and the autonomous community of Madrid (Royal Decree 631/2010, of May 14 and Decree 36/2011, of June 2). It teaches classical repertoire (in all its styles) with traditional sheet music. All this endows it with a wide margin of cultural explicitation, or awareness of the elements learned, because they have been developed in external representations systems such as musical notation. Activities are organised in weekly oneto-one and group classes, in addition to auditions, which are primarily individual, and 
exams, such as the final exam at the end of the course, which lead to the award of an official degree.

Flamenco culture. In the opposite place, we have the flamenco culture, for which we focused on participants of gypsy ethnicity. If conceptions and beliefs are culturally built, it would be necessary to observe communities in which the differences go beyond musical differences, such as may be true of the gypsy community. This would imply a social construction arising from areas of everyday interaction and not just in the musical domain, although we observe them in the latter. Moreover, in previous studies we have found that their discourse marks values that differ significantly from those of non-gypsies within flamenco (Casas et al., 2013). The flamenco culture does not use official institutions but relies on personal pedagogical projects at a private academy or the teacher's home. The teacher is a reference figure due to his (typically) career, and has not passed any kind of selective test. Participants also practice many hours in a family setting and with peers, during which they exchange exercises, falsetas (variations) and pieces inherited from teachers or composed by themselves. Nowadays they often use video/audio recordings as tools, particularly on mobile phones, but they do not use any kind of notation. There are no exams or specific accreditations.

Like the studies of Karlsen (2012) and Sexton (2012), musical competence of gypsy students may not be completely recognised at school in Spain. The first step would thus be to better understand the cultures that we have in an educational context.

Jazz culture. Classical and flamenco music represent the poles of the formal-informal continuum. Jazz is in an intermediate position that we shall call non-formal and define as one that uses procedures or instances that break one or some of the formal rules. In the jazz culture, even in more institutionalised situations, there are at the same time nonformal or informal learning structures such as jam sessions, which are essential to learner training. At jam sessions, the musicians listen to performers in a natural musical context (at clubs), where they can approach the stage (which is usually at the same level as the audience) and take part by starting to play and stopping when they feel the urge to do so. This kind of session is usually held on a weekly basis and provides an opportunity for playing with professional musicians, social enjoyment and learning. In Madrid, jazz higher education is still imparted at independent schools that award their own degrees, which are not officially recognised. They mainly play standards in which the melody is written in traditional notation and the harmony in chord symbol notation (chart), so that the learner has an outline of the piece from the beginning.

Based on the description of the cultures selected for this study, we will present our research questions, which will help us understand different systems of musical education and their relationship with their social setting.

Our first question is whether participant discourse differs significantly among the three cultures studied. In other words, might the learner prefer one or another type of theory depending on the musical culture he/she belongs to?

Our second question is about the homogeneity of the theories within each culture considering the three educational dimensions. Do participants in a given culture maintain the same implicit theories regarding the learning, teaching and evaluation dimensions? 
Our third question is how the three educational dimensions influence the choice of theory. Are teaching and learning described differently in cultures that use musical notation and those that do not? Is evaluation the same in cultures with and without official accreditation?

We chose to observe guitarists because the guitar is the common instrument to the three largest cultures. The sample was selected among musicians with a semi-professional level of learning, who could still think and express themselves as learners, while at the same time having considerable experience of the culture and playing in several public concerts a year. The great advantage of asking semi-professional learners is that there are processes that they do not yet automatically control as an expert would. Thus, they may even verbalise procedures and strategies because they have not yet been encapsulated.

Previous studies on learners' conceptions about music education focused on beginner, elementary and professional levels (Bautista et al., 2010, 2012; López-Íñiguez \& Pozo, in press; Marín et al., 2013). But there is no study of learners who have spent more than 10 years immersed in a culture and have played only the music of their own culture. To answer our research questions we needed participants who had undergone a process of enculturation sufficiently large. We excluded any who played in two or more cultures, as they would involve variables outside the scope of this study. This greatly limited the population for the sample.

\section{Method}

\section{Participants}

The participants were 30 guitarists. Nine of them belong to Classical culture (4 male, 5 female), aged 19 to 29 years $(M=24.7 ; S D=3.6)$ and spent over 10 years studying music in formal realms like the conservatory, and are studying for a Tertiary Degree (which corresponds to a Bachelor of Music Degree) or Master of Music Studies. Most of their families had some relationship with amateur music. Eleven participants belong to Flamenco culture $(11 \text { male })^{1}$, aged 15 to 25 years $(M=16.82 ; S D=2.96)$, most have not completed compulsory secondary education and have been studying the guitar between one and five years with a specific teacher. There were professional musicians in all their families. Ten participants belong to Jazz culture (9 male, 1 female), aged 26 to 42 years $(M=29.6$; SD $=4.93$ ). They have a College Degree in non-musical studies and most have studied for a Professional Degree in music (prior to Tertiary studies). Their families have no relation to learning music.

We first contacted participants through teachers in each culture. The sample is not limited to the students of these teachers; but those students whose profile was specific to a given culture all had a specific teacher. The classical musicians were from Real Conservatorio Superior de Música de Madrid. Jazz musicians were from Escuela de Música Creativa in Madrid, Escuela de Música Creativa in Buenos Aires and Centro Superior de Música del País Vasco, Musikene. Flamenco musicians were selected from students of the most renowned teachers in the gypsy neighbourhoods in Madrid. 


\section{Materials}

A multiple-choice questionnaire was used to identify the implicit theories held by music learners. The questionnaire was designed by Bautista et al. (2012), and adapted to the typical situations of learning, teaching and evaluating guitar playing in each culture. The multiple choice questionnaire poses 16 situations (dilemmas) which are typical of dimensions such as the teaching, learning and evaluation of musical interpretation, followed by three different answer options which are based on the implicit theory framework (direct, interpretative and constructive theories), according to their epistemological, ontological and conceptual assumptions. Participants were asked to choose only one answer.

The questions for the learning dimension (5 questions) asked about aspects related to cooperative learning, memory, motivation, technical difficulties and approach to new repertoire. The questions for teaching dimension (5 questions) asked about difficulty of the piece and difficulties faced by the learner, learner autonomy in class, characteristics of the ideal teacher, homework assignment and how to start a new piece when faced with incomplete information. The questions for the evaluation dimension (6 questions) focused on subjects such as student performance, interest and autonomy, non-standard versions in each culture and learning to play well (6 questions).

Similar questionnaires have been very useful in studies of conceptions in the fields of learning and teaching music (Bautista et al., 2009, 2010) and others (Pozo et al., 2006). The following are examples for each educational dimension in the questionnaire (Table 4).

\section{Design and procedure}

We conducted a simple, prospective ex post facto study (see Montero \& León, 2007), since we first formed the groups according to the independent variable - CULTURE - and then gathered information on the dependent variable - Conceptions of Teaching-Learning in three EDUCATIONAL DIMENSIONS: learning, teaching and evaluation.

Three levels were defined for the variable CULTURE: classical $(\mathrm{CL})$, jazz (JZ) and flamenco (FL) musicians.

A total of 30 semi-structured interviews were conducted. Guitar learners from the three cultures answered the abovementioned multiple-choice questionnaire. Learner participation (voluntary, without compensation) was 100\%. For each question, they were asked to choose one answer out of three (which referred to each of the three teaching-learning conceptions). The same researcher conducted all interviews. Students were interviewed rather than presented with the written questions because some of the participants might have had difficulty with reading comprehension. The oral interview also enabled us to enquire more deeply into each of the questions according to the participants' answers, asking them to clarify any aspects that were not well defined. The interviews were completed by the middle of the first trimester in the 2010 course.

\section{Results}

Descriptive statistics were calculated from the frequency with which each implicit theory was chosen according to the variable CULTURE. We assigned a score of 0 to the Direct 
Table 4 Examples of questions for each educational dimension in the multiple choice questionnaire, with answers corresponding to implicit theories, presented here as (a) direct theory; (b) interpretative theory and (c) constructive theory

\section{LEARNING DIMENSION}

One of your students has been practising the same repertoire for some months. However, because of his technical difficulties, most of the pieces could still be improved on. Why this is happening?

Most likely, the student is ...

a) ... not practising enough. I would recommend he practice more. It takes perseverance to solve technical difficulties.

b) ... studying wrongly. I would recommend he solve his technical problems by following my instructions.

c) ... studying without considering specific musical outcomes. I would recommend he think first about the musical idea, and then, about the technical skills.

\section{TEACHING DIMENSION}

In a normal one-to-one lesson, a student of one of your partners cannot play a piece because it is technically very demanding. In your opinion, what could the teacher do to help her improve the piece?

a) Play the passage slowly for the student, so that she could observe how it should be played, and then assign technical exercises for homework.

b) Explain what the difficulties are and give instructions to solving them, making sure that she understands what to do.

c) Ask different questions in order to help her think and reason about the reasons for the mistakes and how to work them out.

\section{ASSESSMENT DIMENSION}

In your opinion, the assessment of the instrumental lessons is good above all for ...

a) ... teachers to check the students' musical knowledge and to grade their playing at the end of every academic term.

b) ... teachers to grade the performance of the students and to analyse which aspects should be corrected during subsequent lessons or academic years.

c) ... students, so that after talking with their teachers, they can reflect upon their own learning and realise which their strong and weak points are.

Theory, assuming that it ignores the explicit intervention of the learner's psychological processes and is based on the epistemological assumption of a single, unquestionable reality, a score of 1 to the Interpretative Theory and 2 to the Constructive Theory. As a novelty compared with previous research in this field, we established a continuum along which intermediate profiles would probably be the most typical. We expected to find an interpretation of degree rather than classification, which could be used as a heuristic to find differences that would otherwise be impossible to establish due to the small sample size (owing to the characteristics of the population studied, as explained in Method). The values were divided by the maximum score so that each participant or group of participants could be scored along a continuum of 0 to $100 \%$, representing a continuum from the most direct to the most constructive conception. 
Table 5 Averages and standard deviations according to each Culture and Educational dimension

\begin{tabular}{lllll}
\hline \hline & $\begin{array}{l}\text { FLAMENCO } \\
\mathrm{n}=11\end{array}$ & $\begin{array}{l}\text { JAZZ } \\
\mathrm{n}=10\end{array}$ & $\begin{array}{l}\text { CLASSICAL } \\
\mathrm{n}=9\end{array}$ & $\begin{array}{l}\text { Average } \\
\mathrm{n}=30\end{array}$ \\
\hline Conditions/Teaching & $\mathrm{M}=0.37$ & $\mathrm{M}=0.63$ & $\mathrm{M}=0.72$ & $\mathrm{M}=0.56$ \\
& $\mathrm{SD}=.13$ & $\mathrm{SD}=.16$ & $\mathrm{SD}=.23$ & \\
Processes/Learning & $\mathrm{M}=0.46$ & $\mathrm{M}=0.60$ & $\mathrm{M}=0.59$ & $\mathrm{M}=0.55$ \\
& $\mathrm{SD}=0.14$ & $\mathrm{SD}=0.12$ & $\mathrm{SD}=0.18$ & \\
Results/Assessment & $\mathrm{M}=0.64$ & $\mathrm{M}=0.74$ & $\mathrm{M}=0.73$ & $\mathrm{M}=0.70$ \\
& $\mathrm{SD}=0.07$ & $\mathrm{SD}=0.09$ & $\mathrm{SD}=0.11$ & \\
Average & $\mathrm{M}=0.49$ & $\mathrm{M}=0.66$ & $\mathrm{M}=0.68$ & \\
\hline \hline
\end{tabular}

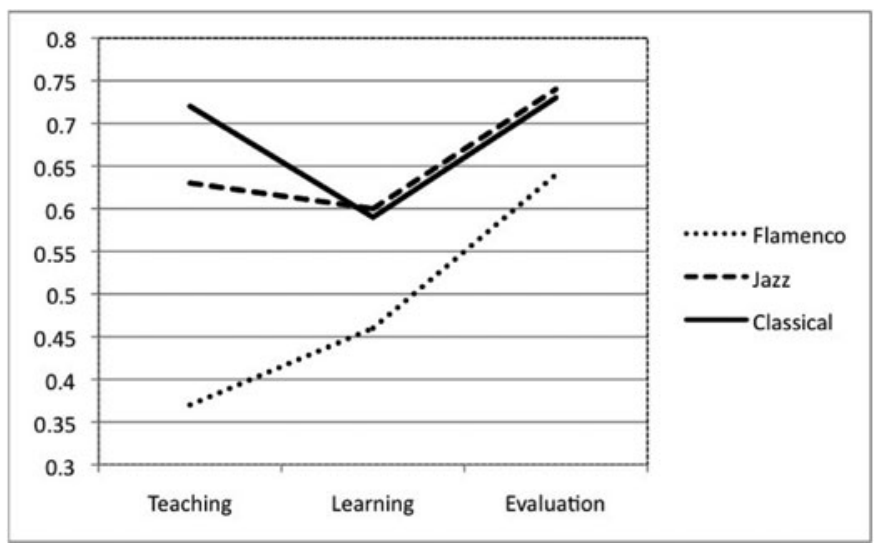

Fig. 1 Proportion of Constructivism in the answers from the three cultures in interaction with the three Educational dimensions

A $3 \times 3$ Analysis of Variance was applied ( 3 cultures, analysed between subjects $\times 3$ educational dimensions, analysed within subjects).

Table 5 shows the means, standard deviations and number of observations for each of the nine combinations arising from this $3 \times 3$. It shows the proportion for the constructivism mean value for each educational dimension in each of the three cultures. Scores were transformed into proportions along a continuum in which the lowest score for each question (and dimension) was 0 and the highest score was 1, in order to allow comparison among dimensions containing different numbers of items.

Following León and Montero (2003) in the interpretation of factorial designs, we start by describing the interaction between the two variables, where we found a significant effect $\left(\mathrm{F}(2,54)=2.69, \mathrm{p}<0.05, \eta^{2}=0.166,1-\beta=0.66\right)$.

Figure 1 shows the results obtained for the answers from the Cultures (FL, JZ and $\mathrm{CL}$ ) interacting with Educational Dimensions (teaching, learning and evaluation). In the right area of the figure, there is a pattern of parallel lines for the three Cultures, with FL having 
the lowest score. All cultures score higher in the evaluation dimension. We will respond later on as to whether or not these two issues are significant, but this information can be summarised in the principal effects.

In the left area of Fig. 1, the lines are not parallel, so we cannot summarise the information in the principal effects. We need to test whether the distances between the three cultures are significant and whether there is consistency among the answers to the three dimensions within each culture.

All three cultures have similar patterns for Learning and Evaluation. The greatest difference between cultures is for the Teaching dimension.

Below, we will break down the interaction of the simple effects to test whether the distances between the three cultures are significant in the Teaching dimension, and whether there is consistency among the answers to the dimensions within the FL culture.

Univariate analysis of variance was performed. We will begin by presenting the between-subject analysis, in which the three Cultures are compared.

\section{Between-subject analysis}

Simple ANOVA showed that participant Culture has a significant effect on the degree of constructivism of the participant's conception only in the Teaching dimension $F(2,27)=$ 10.81, $p<0.001$.

Post hoc multiple comparisons showed that scores for the teaching dimension differed significantly between FL and JZ $(p<0.01)$ and between FL and CL musicians $(p<0.01)$. There was no significant difference between JZ and CL musicians.

Global means are higher for $\mathrm{CL}$ musicians, i.e. CL make more constructive choices, although a detailed analysis shows that JZ musicians score higher - though not significantly on both learning and evaluation dimensions.

The within-subject analysis is presented below, to see how participants answered within each culture.

\section{Within-subject analysis}

For FL, ANOVA showed that cultural group has significant effects on the answers provided for the different educational dimensions, $F(2,20)=18.22, p<0.001$. Within-subject contrast tests revealed significant differences $F(1,10)=33.91, p<0.01$, with answers to the Evaluation dimension differing significantly $(p<0.05)$ from those to Teaching and Learning, while no significant difference was found between the latter two.

For JZ, ANOVA showed that cultural group has significant effects on the answers provided for different educational dimensions $F(2,18)=6.34, p<0.01$. However, withinsubject contrast tests did not reveal significant differences, and the answers to the three dimensions (Teaching, Learning and Evaluation) did not differ significantly from each other.

For $\mathrm{CL}$, ANOVA showed that cultural group has no significant effect on the answers provided for the different educational dimensions.

Finally, after breaking down the simple effects to see the results in more detail, we shall present the results of the chi-square test for those questions for which it was significant. Thus we can see the election profiles in certain questions. 
Table 6 ASR values for the chi-squared test in Question 9

\begin{tabular}{lccc}
\hline \hline \multicolumn{4}{c}{ P.9. How the teacher assigns homework } \\
\hline & Direct & Interpretative & Constructive \\
\hline Flamenco & $3.6^{* *}$ & -1.9 & $-2.1^{* *}$ \\
Jazz & -1.6 & $2.4^{* *}$ & -1.0 \\
Classical & $-2.1^{* *}$ & -0.5 & $3.2^{* *}$ \\
\hline \hline
\end{tabular}

${ }^{*} p<0.5 .{ }^{* *} p<0.01$

Table 7 ASR values for the chi-squared test in Question 13

\begin{tabular}{lccc}
\hline \hline \multicolumn{2}{c}{ P.13. Teachers action after student has resolved a previous difficulty } \\
\hline & Direct & Interpretative & Constructive \\
\hline Flamenco & $2.8^{* *}$ & -0.2 & $-2.6^{* *}$ \\
Jazz & -1.6 & 1.0 & -0.8 \\
Classical & -1.3 & -0.8 & $2.0^{* *}$ \\
\hline \hline
\end{tabular}

${ }^{*} p<0.5 .{ }^{* *} p<0.01$

\section{Teaching dimension}

The answers to questions about the Teaching dimension with scores that differ significantly from the random value expected according to $\chi^{2}$ are shown below. We may thus reject the null hypothesis of equitable distribution of answers from participants belonging to the three cultures regarding the three implicit theories (direct, interpretative and constructive).

For Question 9: (how the teacher assigns homework), the value is significant ( $\chi^{2}$ (4) $=19.74, p=0.001$ ) and the adjusted standardised residuals show that the value for FL is higher than expected for the Direct Theory and lower than expected for the Constructive Theory, i.e. they provide more direct answers and fewer constructive answers. The value for JZ is higher than the expected for the Interpretative Theory. The value for CL is higher than expected for the Constructive and lower than expected for the Direct Theory (Table 6).

In Question 13: (teacher's action after student has resolved a previous difficulty), the value is significant $\left(\chi^{2}(4)=10.01, p=0.040\right)$ and Adjusted Standardised Residuals (ASR) show that the value for FL is higher than expected for the Direct Theory and lower than expected for the Constructive Theory. The value for $\mathrm{CL}$ is higher than expected for the Constructive Theory (Table 7).

There are two more questions whose value is significant with marginal probability, namely questions 12: (How the teacher begins when the student has a difficulty) $\left(\chi^{2}(4)=\right.$ 7.97, $p=0.093)$, for which the ASR show that values for FL are lower than expected for the Constructive Theory, and question 8: (Teacher's instructions when giving the student incomplete information) $\left(\chi^{2}(6)=10.95, p=0.090\right)$, for which the ASR show that the values for JZ are higher than expected for the Direct Theory and lower than expected for the Constructive Theory (Table 8). 
Table 8 ASR values for the chi-squared test in Questions 12 and 8.

\begin{tabular}{|c|c|c|c|}
\hline \multicolumn{4}{|c|}{ P. 12. How the teacher begins when the student has a difficulty } \\
\hline & Direct & Interpretative & Constructive \\
\hline Flamenco & 1.3 & 1.4 & $-2.7^{*}$ \\
\hline Jazz & -0.3 & -1.3 & 1.7 \\
\hline Classical & -1.0 & -0.2 & 1.1 \\
\hline \multicolumn{4}{|c|}{ P.8. Teacher's instructions when giving the student incomplete information } \\
\hline & Direct & Interpretative & Constructive \\
\hline Flamenco & -1.1 & -0.2 & 1.4 \\
\hline Jazz & $2.5^{*}$ & 0.0 & $-2.8^{*}$ \\
\hline Classical & -1.5 & 0.2 & 1.4 \\
\hline
\end{tabular}

${ }^{*} p<0.5 .{ }^{* *} p<0.01$.

Table 9 ASR values for the chi-squared test in Questions 1 and 10.

\begin{tabular}{lccl}
\hline \hline \multicolumn{4}{c}{ P.1. What student difficulties are due to } \\
\hline & Direct & Interpretative & Constructive \\
\hline Flamenco & $3.4^{* *}$ & $-2.4^{* *}$ & -0.4 \\
Jazz & -1.8 & 1.8 & -0.4 \\
Classical & -1.6 & 0.7 & -0.9 \\
\hline \multicolumn{4}{c}{ P.10. How the student begins a new piece } \\
\hline Flamenco & Direct & Interpretative & Constructive \\
Jazz & 1.9 & -1.4 & -0.5 \\
Classical & -1.1 & $2.1^{*}$ & -1.5 \\
\hline \hline
\end{tabular}

${ }^{*} p<0.5 .{ }^{* *} p<0.01$.

\section{Learning dimension}

Question 1 for the Learning dimension (what student difficulties are due to) has a significant value $\left(\chi^{2}(4)=12.13, p=0.016\right)$, and the ASRs show that the values for FL are higher than expected for the Direct Theory and lower than expected for the Interpretative Theory. There is also a question - Question 10 (how guitarists learn musical pieces by heart) - whose value is significant with marginal probability $\left(\chi^{2}(4)=8.59, p=0.072\right)$ and the ASRs show that he value for FL is higher than expected for the Direct Theory, the value for JZ is higher than expected for the Interpretative Theory and the value for $C L$ is higher than expected for the Constructive Theory (Table 9).

\section{Evaluation dimension}

In Question 3 (how the teacher's opinion is useful to the student) the chi-square statistic has marginal probability $\left(\chi^{2}(4)=8.08, p=0.089\right)$ and the ASRs show that the value for FL 
Table 10 ASR values for the chi-squared test in Question 3

\begin{tabular}{lccc}
\hline \hline \multicolumn{3}{c}{ P.3.How the teacher's opinion is useful to the student } \\
\hline Direct & Interpretative & Constructive \\
\hline Flamenco & $2.2^{*}$ & -0.7 & -1.4 \\
Jazz & -0.3 & -1.0 & 1.5 \\
Classical & $-2.0^{*}$ & 1.8 & -0.1 \\
\hline
\end{tabular}

${ }^{*} p<0.5 .{ }^{* *} p<0.01$

is higher than expected for the Direct Theory, while the value for CL is lower than expected for the Direct Theory (Table 10).

\section{Discussion}

Considering the aims set at the beginning of this study and the results obtained, we will answer the first question: Might the learner prefer one or another type of theory depending on the musical culture he/she belongs to? As in previous studies (e.g. López-Íñiguez et al., 2014), we have found that the prevailing conception in all three cultures is interpretative. This is due to the fact that it shares the direct theory's epistemological principle and acts as a bridge towards and hinge with the constructive theory. We shall discuss our first question regarding differences among the learning cultures and show a first description of the participants from the results of $\chi^{2}$ described above.

Learners of FL culture opt for a teaching-learning format which is externally regulated and based on copying. The teacher is the one who decides the pieces that learners are going to play and demonstrates how to play them. Students are significantly less likely to opt for choosing their own pieces. They say that they memorise pieces by repeating fragments and then repeating the entire piece from beginning to end. The opinion of the teacher serves to correct the student as soon as possible. They prefer the teacher to begin by noting what is wrong; telling the student how to solve it, without learners thinking about why, which the teacher has already done. If the student plays well, the teacher can congratulate him, but he must move on to the next part to be corrected. The first conclusion is that gypsy flamenco musicians differ significantly from the other two cultures regarding the Teaching dimension. This shows that its educational conditions are culturally very different from $\mathrm{CL}$ or JZ. FL is a culture centred on oral transmission in which the replication of efficient models is prioritised in order to ensure its preservation, particularly in teaching.

Learners belonging to CL culture opt for student self-regulation. They prefer students to choose their own pieces and it is significantly less likely to be the teacher who chooses and shows the students how to play them. They are less likely to choose the option that the teacher's judgement serves to correct the student as soon as possible. They say that they memorise pieces by singing and clapping, to capture the meaning and the whole idea. For the benefit of the process of motivation, classical students preferred options in which the teacher gets the student to think about why certain things go well, how he has studied 
and what new things he could focus on now. Overall, they express more constructive conceptions than FL participants.

Although we have specified that FL learn music more informally, in the context of the family, they are now under the tutelage of a guitar teacher. This somewhat modifies the continuum described by Trilla (1997) and Folkestad (2006), firstly regarding leadership in the activity (who takes the decisions) - learners reported didactic teaching in both cases, but with more self-regulated learning in the formal context - and secondly, regarding the question of high intentionality and low openness of the task, on the part of the teacher.

At the midpoint, we can see that jazz students argue that the teacher should focus on the student's interests and skills. Yet JZ teachers do not grant the learner the same degree of choice as teachers in the classical setting do. Students say they memorise the pieces by understanding the parts of the form and the relationship between chords. It is worth noting that when JZ teachers give a student incomplete information, there is significant probability that they would prefer the student not to test the topic on his own, in order not to 'learn with mistakes'. Instead, they might have chosen to allow the student to try it himself and learn from his mistakes, if any. This fits even better within the ideological basis of the JZ culture, in which the chart itself is incomplete information that needs to be built by the performer.

The three cultures were found to be more similar than expected in the Evaluation dimension, where we had thought that the lack of official accreditation in the non-formal and informal settings might make a difference to the conceptions. However, it was here that the highest number of constructive responses was provided and the three cultures were found to be closest, in agreement with the results of López and Pozo (2010) and López-Íñiguez et al. (2014). This may be explained by the fact that in all three traditions, the participants were still undergoing training, but at the same time were semi-professional and performing regularly in public under their own responsibility.

We shall now discuss our second question about the homogeneity within each culture regarding the three dimensions analysed. The significant difference within FL is surprising due to the difference between the evaluation dimension and the teaching dimension, for which the pattern is much more direct. This opens questions about the coexistence of conceptions in 'harmony' that we have been supporting, or Entwistle's (2007) 'representational multiplicity'. It is also noteworthy that direct and constructive theories can coexist consistently within the same participants, when the literature on the subject supports the need for a conceptual break or change to activate constructivist conceptions and therefore direct-constructive profiles had not been found before (López-Íñiguez et al., 2014).

Considering these three cultures simultaneously, we should pay special attention to the homogeneity of the flamenco culture, which appears as atypical and deserves further study so that it may be understood more comprehensively. In designing the study, it should consider and respect all groups, regardless of their race, ethnicity, religion or culture. Then, considering the impact of various methodologies on different groups, this moves us to seek other methodologies to establish new parameters with cultures that have a different approach to reality. These new parameters could then be evaluated in the cultures with academic tradition.

Finally, we will discuss the third question about the influence of the educational dimensions. We interpret that the participants - in our case students - have more complex 
conceptions in the dimensions that make them think about what they would demand from the other role (the teacher) regarding help that the student himself/herself needs. In other words, when the student thinks about teaching or evaluation and expresses what he/she would expect from the teacher, he/she is more constructive than when selecting an option regarding his/her own learning. More interpretative or even direct responses are preferred in learning.

In summary, the contributions of popular music benefit not only formal education in mandatory educational fields, but can also lead to rethinking the format of 'excellence' in higher education (Karlsen, 2010), since other ways are viable in other cultures. We could pay particular attention to whether the type of formalised music education might hinder learning in people who have been trained in more informal spheres (Feichas, 2010).

To conclude, we do not intend to say whether one culture is above or below others regarding a given kind of values previously established from the conceptions of one of the cultures (fully academic). This analysis shows the points in which there are significant differences of a certain kind, which are crucial to understanding education in each social group. The theories about cognitive change have usually focused on the endpoints of development (skills in activities such as operational, formal and scientific reasoning and practices related to reading-writing). These are valuable goals, but are linked to their own context and culture, like any other developmental goal or endpoint valued by a given community (Rogoff, 1990). This perspective may allow us to enter into ulterior analyses precisely of those aspects that have been highlighted here. We venture to suggest that practices of a certain kind might be in tune with thinking of a certain kind, but we must be alert to the intrinsic values from which those practices are emphasised socially.

\section{Note}

1 The sample, which has many more male than female participants, is not a matter of bias, but reality. In popular urban music, women rarely participate in any group as instrumentalists (Green, 1997).

\section{References}

BAUTISTA, A. (2009) Concepciones de profesores y alumnos de piano sobre la enseñanza y el aprendizaje de partituras musicales [Conceptions of piano teachers and students about teaching and learning of musical scores]. (Unpublished doctoral dissertation). Universidad Autónoma de Madrid, Spain.

BAutistA, A., PÉREZ ECHEVERríA, M. P., POZO, J. I. \& BRIZUELA, B. (2009) Piano students' conceptions of musical scores as external representations: A cross-sectional study. Journal of Research in Music Education, 57, 181-202.

BAUTISTA, A., PÉREZ ECHEVERríA, M. P. \& POZO, J. I. (2010) Music performance teachers' conceptions about learning and instruction: a descriptive study of Spanish piano teachers. Psychology of Music, 38, 85-106.

BAutistA, A., PÉREZ EChEVERríA, M. P., POZO, J. I. \& BRIZUELA, B. (2012) Piano students' conceptions of learning, teaching, assessment, and evaluation. Estudios de Psicología, 33, 79-104.

BLACKING, J. (1978) Some problems of theory and method in the study of musical change. Yearbook of the International Folk Music Council, 9, 1-26.

BRANSFORD, J. D., BROWN, A. \& COOKING, P. (2000) How People Learn: Brain, Mind, Experience, and School. Washington, DC: National Academic Press. 
CASAS, A. \& POZO, J. I. (2008) ¿Cómo se utilizan las partituras en la enseñanza y el aprendizaje de la música? [How scores are used in the teaching and learning of music?]. Cultura y Educación, 20, 49-62.

CASAS, A., POZO, J. I. \& SCHEUER, N. (2013) Tell s who you are, and we tell you what you learn. Manuscript in preparation, Department of Psychology, Universidad Autónoma de Madrid, Spain.

CHAFFIN, R., IMREH, G., LEMIEUX, A. \& CHEN, C. (2003) "Seeing the big picture": Piano practice as expert problem solving. Music Perception, 20, 465-490.

DE CORTE, E. (1996) New perspectives on learning and teaching in higher education. In A. Burgen (Ed.), Goals and Purposes of Higher Education in the 21st Century (pp. 112-132). London: Jessica Kingsley Publishers.

DECRETO 36/2011, OF JUNE 2 (B.O.C.M. of 16 June 2011) Plan de Estudios para la Comunidad de Madrid, de las enseñanzas artísticas superiores de Grado en Música [Curriculum for the Community of Madrid, of the Artistic Bachelor of Music Degree]. Madrid, Spain.

DONALD, M. (1991) Origins of the Modern Mind. Three Stages in the Evolution of Culture and Cognition. Cambridge, MA: Harvard University Press.

DONALD, M. (1993) Précis of origins of the modern mind: three stages in the evolution of culture and cognition. Behavioral and Brain Sciences, 16, 737-791.

DUKE, R. A., SIMMONS, A. L. \& CASH, C. D. (2009) It's not how much; it's how: Characteristics of practice behaviour and retention of performance skills. Journal of Research in Music Education, 56, 310-321.

DUNBAR-HALL, P. \& WEMYSS, K. (2000) The effects of the study of popular music on music education. International Journal of Music Education, 36, 23-34.

ELLIOTT, D. (1989) Key concepts in multicultural music education. International Journal of Music Education, 13, 11-18.

ENTWISTLE, N. J. (2007) Conceptions of learning and the experience of understanding: thresholds, contextual influences, and knowledge objects. In S. Vosniadou, A. Baltas \& X. Vamvakoussi (Eds.), Reframing the Conceptual Change in Learning and Instruction (pp. 123-144). Amsterdam: Elsevier.

FEICHAS, H. (2010) Bridging the gap: informal learning practices as a pedagogy of integration. British Journal of Music Education, 27, 47-58.

FOLKESTAD, G. (1998) Musical learning as a cultural practice. As exemplified in computer-based creative music making. In B. Sundin, G. McPherson \& G. Folkestad (Eds.), Children Composing (pp. 97-134). Malmö: Lund University, Malmö Academy of Music.

FOLKESTAD, G. (2004) A meta-analytic approach to qualitative studies in music education: a new model applied to creativity and composition. Bulletin of the Council for Research in Music Education, 161/162, 83-90.

FOLKESTAD, G. (2006) Formal and informal learning situations or practices vs. formal and informal ways of learning. British Journal of Music Education, 23, 135-145.

GEORGII-HEMMING, E. \& WESTVALL, M. (2010) Music education - a personal matter? Examining the current discourses of music education in Sweden. British Journal of Music Education, 27, 21-33.

GOWER, A. (2012) Integrating informal learning approaches into the formal learning environment of mainstream secondary schools in England. British Journal of Music Education, 29, 13-18.

GREEN, L. (1997) Music, Gender, Education. Cambridge: Cambridge University Press.

GREEN, L. (2001) How Popular Musicians Learn: A Way Ahead for Music Education. Aldershot: Ashgate.

GREEN, L. (2008) Music, Informal Learning and the School: A New Classroom Pedagogy. Aldershot: Ashgate.

GREEN, L. (Ed.) (2011) Learning, Teaching, and Musical Identity. Voices across Cultures. Bloomington, IN: Indiana University Press.

GRUSON, L. M. (1988) Rehearsal skills and musical competence. Does practice make perfect? In J. A. Sloboda (Ed.), Generative Processes in Music (pp. 91-112). Oxford: Clarendon Press.

HALLAM, S. (2007) Music Psychology in Education. London: Institute of Education, University of London.

HOWE, M. J. A. \& SLOBODA, J. A. (1991) Young musicians' accounts of significant influences in their early lives. 1. The family and the musical background. British Journal of Music Education, 8, 39-52. 
HULTBERG, C. (2002) Approaches to music notation: the printed score as a mediator of meaning in Western tonal tradition. Music Education Research, 4, 185-197.

JORGENSEN, H. (2002) Instrumental performance expertise and amount of practice among instrumental students in a conservatoire. Music Education Research, 4, 105-119.

KARLSEN, S. (2010) BoomTown Music Education and the need for authenticity - informal learning put into practice in Swedish post-compulsory music education. British Journal of Music Education, 27, 35-46.

KARLSEN, S. (2012) Multiple repertoires of ways of being and acting in music: immigrant students' musical agency as an impetus for democracy. Music Education Research, 14, 131-148.

KEMBER, D. (2001) Beliefs about knowledge and the process of teaching and learning as a factor in adjusting to study in higher education. Studies in Higher Education, 26, 205-221.

KLATTER, E. B., LODEWIJKS, H. G. L. C. \& AARNOUTSE, C. A. J. (2001) Learning conceptions of young student in the final year of primary education. Learning and Instruction, 11, 485-516.

LAMONT, A., HARGREAVES, D. J., MARSHALL, N. A. \& TARRANT, M. (2003) Young people's music in and out of school. British Journal of Music Education, 20, 229-241.

LEÓN, O. G. \& MONTERO, I. (2003) Métodos de Investigación en Psicología y Educación [Research Methods in Psychology and Education] (3rd ed.). Madrid: McGraw-Hill.

LILLIESTAM, L. (1996) On playing by ear. Popular Music, 15, 195-216.

LÓPEZ, G. \& POZO, J. I. (2010) What could I do to play this piece ... ? Conceptions of cello beginner students about learning processes. In Proceedings of the 3rd International Conference of Students of Systematic Musicology. Cambridge, 13-15 September.

LÓPEZ-ÍNIIGUEZ, G. \& POZO, J. I. (2013) The influence of teachers' conceptions on their students' learning: Children's understanding of sheet music. British Journal of Educational Psychology. Advance online publication. doi:10.1111/bjep.12026.

LÓPEZ-í̃̃IGUEZ, G. \& POZO, J. I. (in press) Like teacher, like student? Conceptions of children from traditional and constructive teachers regarding the teaching and learning of string instruments. Cognition and Instruction.

LÓPEZ-ÍNIIGUEZ, G., POZO, J. I. \& DE DIOS, M. J. (2014) The older, the wiser? Profiles of string teachers with different experience, regarding to teaching, learning and evaluation. Psychology of Music, 42, 157-176. doi:10.1177/0305735612463772.

MARÍN, C., PÉREZ ECHEVERRíA, M. P. \& HALLAM, S. (2012) Using the musical score to perform: a study with Spanish flute students. British Journal of Music Education, 29, 193-212. doi: 10.1017/S0265051712000046.

MARÍN, C., SCHEUER, N. \& PÉREZ-ECHEVERRÍA, M. P. (2013) Formal music education not only enhances musical skills, but also conceptions of teaching and learning: a study with woodwind students. European Journal of Psychology of Education, 28, 781-805.

MCPHERSON, G. E. (2005) From child to musician: skill development during the beginning stages of learning an instrument. Psychology of Music, 33, 5-35.

MIDDLETON, R. (1981) Popular music, I, 4: Europe \& North America: Genre, form, style. In Middleton, R. \& Horn, D. (Eds), Popular Music. Folk or Popular? Distinctions, Influences, Continuities. Cambridge: Cambridge University Press.

MIDDLETON, R. (1990) Studying Popular Music. Milton Keynes: Open University Press.

MONTERO, I. \& LEÓN, O. (2007) A guide for naming research studies in psychology. International Journal of Clinical and Health Psychology, 7, 847-862.

OLSON, D. R. \& BRUNER, J. S. (1996) Folk psychology and folk pedagogy. In D. R. Olson \& N. Torrance (Eds), Handbook of Education and Human Development: New Models of Learning, Teaching and Schooling (pp. 9-27). Malden, MA: Blackwell.

PÉREZ ECHEVERRÍA, M. P., MATEOS, M., POZO, J. I. \& SCHEUER, N. (2001) En busca del constructivismo perdido. [In search of lost construtivism]. Estudios de Psicología, 22(2), 155-173. 
PETERSON, E. R. \& IRVING, S. E. (2008) Secondary school students' conceptions of assessment and feedback. Learning and Instruction, 18, 238-250.

PIAGET, J. (1974) Réussir et comprendre. Paris: P.U.F.

POZO, J. I. \& GÓMEZ CRESPO, M. A. (2005) The embodied nature of implicit theories: the consistency of ideas about the nature of matter. Cognition and Instruction, 23, 351-387.

POZO, J. I., SCHEUER, N., PÉREZ ECHEVERRÍA, M. P., MATEOS, M., MARTíN, E. \& DE LA CRUZ, M. (Eds.) (2006) Nuevas formas de pensar la enseñanza y el aprendizaje. Las concepciones de profesores y alumnos. Barcelona: Graó.

REAL DECRETO 631/2010, OF MAY 14 (B.OE. of June 5, 2010) Contenido básico de las enseñanzas artísticas superiores de Grado en Música establecidas en la Ley Orgánica 2/2006, de 3 de mayo, de Educación [Basic content of the Artistic Bachelor of Music Degree established in the Organic Law 2/2006, of 3 May, on Education]. Spain.

ROBINSON, T. (2010) How Popular Musicians Teach (Unpublished doctoral dissertation). Department of Music, University of Sheffield.

ROBINSON, T. (2012) Popular musicians and instrumental teachers: the influence of informal learning on teaching strategies. British Journal of Music Education, 29, 359-370.

ROGOFF, B. (1990) Apprenticeship in Thinking. Cognitive Development in Social Context. New York: Oxford University Press.

SAWYER, K. (Ed.) (2006) Cambridge Handbook of the Learning Sciences. New York: Cambridge University Press.

SCHEUER, N., DE LA CRUZ, M. \& POZO, J. I. (2002) Children talk about learning to draw. European Journal of Psychology of Education, 17, 101-114.

SCHIPPERS, H. (1996) Teaching world music in the Netherlands: towards a model for cultural diversity in music education. International Journal of Music Education, 27, 16-23.

SEIFRIED, S. (2006) Exploring the outcomes of rock and popular music instruction in high school guitar class: a case study. International Journal of Music Education, 24, 168-177.

SEXTON, F. (2012) Practitioner challenges working with informal learning pedagogies. British Journal of Music Education, 29, 7-11.

SHAH, S. M. (2006) Popular music in Malaysia: education from the outsider. International Journal of Music Education, 24, 132-139.

SPERBER, D. (1996) Explaining Culture. A Naturalistic Approach. Oxford: Blackwell.

TAGG, Ph. (1982) Analysing popular music: theory, method and practice. Popular Music, 2, 37-65.

TRILLA, J. (1997) Relaciones entre la educación formal, la no formal y la informal [Relations between formal, non-formal and informal education]. In La educación fuera de la escuela (pp. 187-196). México: Ariel.

VYGOTSKY, L. S. (1933/1978) Mind in Society. The Development of Higher Psychological Processes. M. Cole, V. John-Steiner, S. Scribner, E. Souberman (Eds). Cambridge, MA: Harvard University Press.

WANG, J. C. \& HUMPHREYS, J. T. (2009) Multicultural and popular music content in an American music teacher education program. International Journal of Music Education, 27, 19-36.

WILLIAMON, A., VALENTINE, E. \& VALENTINE, J. (2002) Shifting the focus of attention between levels of musical structure. European Journal of Cognitive Psychology, 14, 493-520.

WOODY, R. H. (1999) The relationship between explicit planning and expressive performance of dynamic variations in an aural modelling task. Journal of Research in Music Education, 47, 331-342.

WRIGHT, R. \& KANELLOPOULOS, P. (2010) Informal music learning, improvisation and teacher education. British Journal of Music Education, 27, 71-87.

Amalia Casas-Mas teaches educational psychology and sociology of music education at the Royal Conservatory of Music in Madrid, Spain. She has a PhD in psychology in the field of Psychology of Music Learning. Her topic focuses on different ways of learning 
music in formal and informal contexts, specialising in Flamenco music communities. She has published in Estudios de Psicología and in Cultura y Educación.

Juan-Ignacio Pozo is Professor at the Faculty of Psychology of Universidad Autónoma de Madrid, Spain, where he teaches topics related to the psychology of learning. His research focuses on the processes of knowledge acquisition in different subject domains, such as science, history, geography, and also music. He has studied how to change teachers' and learners' conceptions of learning in order to transform instructional settings, publishing several books and papers about learning and teaching in those domains.

Ignacio Montero is Associate Professor of Research Methods in Psychology and Education at Universidad Autónoma of Madrid. He has investigated issues related to development of self-regulation through private speech. Recently he has edited the volume Private Speech, Executive Functioning, and the Development of Verbal Self-regulation (Cambridge University Press), in collaboration with Winsler and Fernyhough, as well as several papers on this topic. 